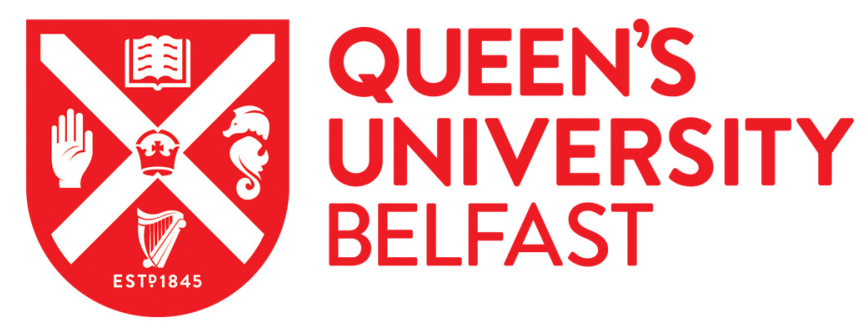

\title{
Resistance of alkali-activated binders to organic acids found in agri- food effluents
}

Aiken, T., Kwasny, J., \& Sha, W. (2021). Resistance of alkali-activated binders to organic acids found in agrifood effluents. ASCE Journal of Materials in Civil Engineering, 33(4), [04021024].

https://doi.org/10.1061/(ASCE)MT.1943-5533.0003635

Published in:

ASCE Journal of Materials in Civil Engineering

Document Version:

Peer reviewed version

Queen's University Belfast - Research Portal:

Link to publication record in Queen's University Belfast Research Portal

Publisher rights

(C) 2020 American Society of Civil Engineers.

This work is made available online in accordance with the publisher's policies. Please refer to any applicable terms of use of the publisher.

\section{General rights}

Copyright for the publications made accessible via the Queen's University Belfast Research Portal is retained by the author(s) and / or other copyright owners and it is a condition of accessing these publications that users recognise and abide by the legal requirements associated with these rights.

Take down policy

The Research Portal is Queen's institutional repository that provides access to Queen's research output. Every effort has been made to ensure that content in the Research Portal does not infringe any person's rights, or applicable UK laws. If you discover content in the Research Portal that you believe breaches copyright or violates any law, please contact openaccess@qub.ac.uk. 


\section{Resistance of alkali-activated binders to organic acids found in agri-food effluents}

2

3 Authors: Timothy A Aiken, Ph.D. ${ }^{1}$; Jacek Kwasny, Ph.D. ${ }^{2}$ and Wei Sha, Ph.D., D.Sc. ${ }^{3}$

5

6

7

8

9

10

11

${ }^{1}$ Postdoctoral Researcher, School of Natural and Built Environment, Queen's University Belfast, Stranmillis Road, Belfast, BT9 5AG, UK (corresponding author). Email: taiken02@qub.ac.uk

${ }^{2}$ Postdoctoral Researcher, School of Natural and Built Environment, Queen's University Belfast, Stranmillis Road, Belfast, BT9 5AG, UK. Email: j.kwasny@qub.ac.uk

${ }^{3}$ Professor, School of Natural and Built Environment, Queen's University Belfast, Stranmillis Road, Belfast, BT9 5AG, UK. Email: w.sha@qub.ac.uk

Abstract

Organic acids such as acetic and lactic acid are prevalent in agricultural and food effluents. They pose a considerable pollution threat and must be collected and stored safely before treatment and release. They cause significant damage to cementitious materials, reducing the service life of structures. In this study the resistance of alkali-activated fly ash and slag blended binders to organic acids was studied and a comparison with ordinary Portland cement binders was carried out. Findings demonstrate that alkali-activated binders with increased fly ash content have marginally better resistance to acetic acid but mixes with increased slag content have better resistance to lactic acid. This is due to the solubility of the calcium and aluminium salts of acetic and lactic acid. Overall the performance of the alkali-activated binders was better than that of the ordinary Portland cement binder with lower mass and strength losses observed. This was attributed to their lower calcium content with less vulnerable phases such as calcium hydroxide and ettringite. Instead the C-S-H type gels in alkali-activated binders suffered decalcification and dealumination but left behind a silicon rich gel which helped to resist further acid attack.

Author keywords: Alkali-activated binder; lactic acid; acetic acid; durability; degradation; fly ash; slag 
30 The agriculture and food industries produce an abundance of effluents or waste waters which are pollutants if released directly into the environment. This means they need to be collected, stored and treated before being released (Bertron and Duchesne 2013). Therefore, these effluents regularly come into contact with concrete causing considerable damage and reducing the service life of structures. Fig. 1 shows silage effluent leaching out from grass stored in a concrete silo pit as winter feed for livestock. This photograph was taken only a few hours after the grass was initially stored. The effluent continues to flow slowly over the concrete floor for around 6 months per year. After only six years inservice the concrete has suffered considerable damage. The surface has been scaled, with cement paste removed, exposing large aggregates and leaving behind a rough surface. This exposure has also reduced the depth of cover to steel reinforcement and mostly likely caused a reduction in strength and eventually will lead to a shorter than expected service life. The silage effluent mainly consists of acetic and lactic acid and has $\mathrm{pH}$ of around 4.0 (Bertron et al. 2005a; Gruyaert et al. 2012).

Silage effluent is only one example of numerous organic acid media which commonly attack concrete. There are many others including animal feed, vinasse, distillates, molassess, whey and liquid manure (De Belie et al. 1997; Bertron 2013; Bertron et al. 2005b; Castillo Lara and Chagas Cordeiro 2019). These cover a broad range of organic acids including acetic, lactic, propionic, butyric, malic, citric and oxalic. These organic acids are often described as weak acids compared with strong acids such as hydrochloric or nitric. However, in some cases the attack on cementitious materials is more aggressive (Shi and Stegemann 2000). This is because the $\mathrm{pH}$ increase of an organic acid solution in contact with cementitious materials is slower than for strong acids, meaning samples are exposed to a lower $\mathrm{pH}$ for longer. Additionally, at a given $\mathrm{pH}$, the acid concentration is higher for an organic acid solution than for a strong acid solution (Castillo Lara and Chagas Cordeiro 2019).

In recent decades the cement and concrete industry has been under increased pressure to reduce $\mathrm{CO}_{2}$ emissions and the consumption of natural resources. This has led to increased attention for alkaliactivated binders which involve the reaction of an aluminosilicate source with an alkali activator to 
form a hardened binder (Shi et al. 2019). The most commonly investigated aluminosilicate sources are fly ash (FA) and slag as they are residues from coal combustion and steel production, respectively and require limited further processing before they can be used (Rakhimova and Rakhimov 2019). The alkali-activation of FA and slag as single precursors have resulted in niche problems specific to that binder type. Alkali-activated FA normally requires high temperature curing to achieve reasonable strength which is a barrier to widespread use in the concrete industry (Bakharev 2005). Whilst alkaliactivated slag does not require high temperature curing, there are issues regarding its fast setting time (Collins and Sanjayan 1999; Nath and Sarker 2014; Shi et al. 2019). The blending of FA and slag together has reduced the aforementioned issues. Alkali-activated FA/slag blends can be cured at ambient temperature and are less susceptible to fast setting (El-Hassan and Elkholy 2019; Rafeet et al. 2019). Therefore, blended FA/slag systems have generated significant interest in recent years.

The majority of studies which have considered the acid resistance of alkali-activated FA/slag systems have focused on strong acids such as sulfuric and nitric acid (Allahverdi and Škvára 2001, 2005; Lee and Lee 2016; Lloyd et al. 2012). The mechanism of acid attack due to sulfuric acid is unique due to the formation of gypsum which causes expansion and mass increases. Gypsum can also act as barrier for further acid attack (Aiken et al. 2018). Therefore, results need careful interpretation and cannot be correlated with the performance of other acid types. As discussed above the nature and behaviour of cementitious materials differs during exposure to weak organic acids. Therefore, this study focuses on the resistance of alkali-activated FA/slag blends to acetic and lactic acid. A comparison with ordinary Portland cement is also presented. In order for the use of alkali-activated binders to become more widely adopted, increased understanding of their durability is needed.

\section{Materials and experimental methods}

The FA used was supplied by Power Minerals Ltd., Drax Power Station, North Yorkshire, UK. The slag used was obtained from Civil and Marine Ltd-Hanson Company, member of the Heidelberg

83 Cement Group, Essex, UK. The Portland cement (CEM I 42.5N) used, was produced by Quinn 
450-1:2012 (British Standards Institution 2012), BS EN 15167-1:2006 (British Standards Institution 2006) and BS EN197-1:2011 (British Standards Institution 2011), respectively. Table 1 shows the specific gravity and oxide composition of each powder binder component which was obtained by Xray florescence (XRF). The particle size distribution of each powder binder component is shown in Fig. 2. Their X-ray diffraction (XRD) patterns are displayed in Fig. 3. Quartz, mullite and hematite were the main phases found in the FA. The slag was almost completely amorphous with a broad peak or hump between 25 and $35^{\circ} 2 \theta$. The Portland cement had numerous crystalline phases including alite, belite, aluminate, brownmillerite and gypsum. The FA/slag mixes were activated by solutions of sodium silicate and sodium hydroxide. The sodium silicate solution was supplied by Fisher Scientific and consisted of $12.8 \% \mathrm{Na}_{2} \mathrm{O}, 25.5 \% \mathrm{SiO}_{2}$ and $61.7 \%$ water. It had a specific gravity of 1.4 . The sodium hydroxide solution was prepared at $30 \% \mathrm{w} / \mathrm{w}$ by the dissolution of solid commercial grade (99\% purity) sodium hydroxide and was allowed to cool to room temperature prior to preparation of mortars and pastes. It had a specific gravity of 1.33 .

The aggregate used in this study was 0-5 mm lough sand, supplied by Creagh Concrete, Northern Ireland. The oven-dry particle density of the sand was $2695 \mathrm{~kg} / \mathrm{m}^{3}$ and its water absorption was 0.9 and $1.1 \%$ after 1 and $24 \mathrm{~h}$, respectively [BS 812-2 (British Standards Institution 1995)]. The particle size distribution of the sand is shown in Fig. 2 and was determined according to BS 812-103.1:1985 (British Standards Institution 1989). Prior to mixing, moisture was removed from the sand by ovendrying at $100{ }^{\circ} \mathrm{C}$ for a minimum of $24 \mathrm{~h}$. It was then allowed to cool to room temperature before mixing began.

Laboratory grade acetic $(99-100 \%)$ and lactic acid $(\geq 85 \%)$ were used to prepare $0.10,0.31$ and 0.52 $\mathrm{mol} / \mathrm{L}$ acid solutions of each acid type by mixing in the required proportions with distilled water. Acetic and lactic acids have dissociation constants pKa of 4.76 and 3.86 , respectively at $25{ }^{\circ} \mathrm{C}$ (Bertron and Duchesne 2013). 
112 The mix proportions used are presented in Table 2. The mixes were based on initial mix design

113 optimisation carried out by The Geopolymer Team at Queen's University Belfast (Kwasny et al.

114 2018c; Rafeet et al. 2017, 2019; Vinai et al. 2016). The alkali-activated mixes have increased FA

115 content from $30 \%$ (FA/S-30/70) to $80 \%$ (FA/S-80/20). The alkali dosage and alkali modulus were

116 fixed at 7.5 and 1.25 , respectively. The alkali dosage is defined as the percentage of $\mathrm{Na}_{2} \mathrm{O}$ in the

117 binder and the alkali modulus is the ratio of $\mathrm{Na}_{2} \mathrm{O}$ and $\mathrm{SiO}_{2}$ (sometimes referred to as silica modulus).

118 The paste content of all mortar mixes was fixed at 50\% volume. The equivalent pastes were designed

119 with the same composition as mortars, except without the presence of sand. The absorption water is

120 the amount of water needed to bring the sand to saturated surface dry condition. The total added water

121 is the total amount of water needed plus the absorption water, less the water contained within activating solutions. The water/solid ratios were chosen based on recommendations from previous studies (Rafeet 2016; Rafeet et al. 2017) which found that mixes with increased slag content had an increased water demand. Mortar samples were used to assess physical changes due to acid attack as they are more representative of in-service exposure due to the presence of sand. Paste samples were used to assess microstructural changes on the paste itself due to acid attack. Sand can complicate microstructural analysis techniques due to the presence of quartz. Therefore, the mortar samples were used to quantify the extent of the attack while paste samples were used to assess the nature of the attack.

Both mortar and paste samples were prepared with a 101 capacity planar-action high-shear mixer. Firstly, the oven dried sand was placed in the mixing bowl along with half of the total added water and mixed together for 1 min. After 15 mins the powder component (FA and slag or Portland cement) of each mix was added. Finally, the remaining water (and activating solutions if appropriate) was added and mixing continued for 6 mins before casting.

The samples were cast in two layers into $50 \mathrm{~mm}$ three-gang cubic moulds and $100 \mathrm{~mm}$ two-gang cubic moulds, each layer was compacted using a vibrating table. After casting the samples were wrapped in cling film for $24 \mathrm{~h}$ to prevent moisture evaporation. To prevent leaching of alkalis, 
samples were cured at $20 \pm 1{ }^{\circ} \mathrm{C}$ and stored on $15 \mathrm{~mm}$ high spacers above $5 \mathrm{~mm}$ of water in sealed containers throughout where the relative humidity was $>90 \%$ (Kwasny et al. 2018b). Samples were demoulded after $24 \mathrm{~h}$ and returned immediately to their curing containers.

Organic acid resistance of mortars was assessed using an accelerated method, based on the guidelines outlined in ASTM C267 (American Society for Testing and Materials 2012) and previous studies (Aiken 2017; Aiken et al. 2017; Kwasny et al. 2018a). After 21 days curing, the $50 \mathrm{~mm}$ mortar cubes were placed into a water bath $\left(20 \pm 1{ }^{\circ} \mathrm{C}\right)$ until 28 days when their mass was recorded. Subsequently four mortar cubes from each mix were put into individual plastic containers together with acid solutions with concentrations of $0.10,0.31$ and $0.52 \mathrm{~mol} / \mathrm{L}$ of acetic and lactic acid. The acid solution to sample volume ratio in each container was maintained at approximately 0.9 throughout. Each week, visual inspection was carried out, the mass of the mortar cubes was recorded and the acid solution replenished. Prior to their mass being recorded in air, the samples were removed from the container and their surface was gently wiped to remove any excess testing solution. Additionally the $\mathrm{pH}$ of the acid solution was monitored at intervals during each week. After 8 weeks, the average compressive strength was obtained by testing three cubes from each box with a constant loading rate of $50 \mathrm{kN} / \mathrm{min}$. The loading zones were protected with softboard to reduce the effect of uneven surfaces. This method was used instead of capping or grinding to allow immediate testing following acid attack, avoiding testing delays which would have caused issues regarding intermediate sample storage conditions and drying during processing. Prior to testing each sample was removed from the container and its surface was gently wiped to remove any excess testing solution. Control samples which were not exposed to acid were also tested for comparison (stored in water). The fourth specimen was used to visually inspect the alkalinity loss. This was achieved by splitting the cubes and applying phenolphthalein solution on the split surface which highlights (deep pink/purple) the region where the $\mathrm{pH}$ is greater than approximately 9 (Chang and Chen 2006; Chinchón-Payá et al. 2016; Liu et al. 2017). mortar fragments measuring approximately $8 \times 8 \times 20 \mathrm{~mm}$ were sectioned from the core of each cube 


\section{1}

using a diamond saw. Hydration/reaction was stopped by oven drying the samples for $24 \mathrm{~h}$ at $60 \pm 1$ ${ }^{\circ} \mathrm{C}$, then immersing them in acetone for $4 \mathrm{~h}$ and subsequently drying them in a desiccator $\left(20 \pm 1{ }^{\circ} \mathrm{C}\right)$ for a further $24 \mathrm{~h}$. A temperature of $60{ }^{\circ} \mathrm{C}$ was used as previous research (Gallé 2001; Ma 2014) has indicated that using a temperature in this region is more realistic and reduces the effect on pore structure compared with higher temperatures. The pore structure of the samples was determined using a Pascal 140/240 mercury intrusion porosimeter from ThermoFisher Scientific. The mercury contact angle was taken to be $140^{\circ}$.

The volume of voids (VPV) of mortars was assessed according to the standard procedure given in ASTM C642 (American Society for Testing and Materials 2006). This involves recording the mass of samples in various conditions which are given below. This test was carried out on $100 \mathrm{~mm}$ long and $75 \mathrm{~mm}$ diameter cores which were extracted from $100 \mathrm{~mm}$ cubes. Three samples were tested for each mix and the VPV was calculated according to:

$$
\operatorname{VPV}(\%)=\frac{C-A}{C-D} \times 100
$$

where:

$\mathrm{A}=$ Mass in air after oven drying, $\mathrm{g}$

$\mathrm{C}=$ Mass in air after immersion and boiling, $\mathrm{g}$

$\mathrm{D}=$ Apparent mass in water after immersion and boiling, $\mathrm{g}$

The standard recommends an oven drying temperature between 100 and $110^{\circ} \mathrm{C}$. In this study, an oven drying temperature of $40{ }^{\circ} \mathrm{C}$ was used to avoid excessive drying which can cause changes to binding phases such as calcium aluminium silicate hydrate gel within alkali-activated concrete (Ismail et al. 2013).

Equivalent paste samples were exposed to the same cyclic exposure regime for 3 weeks using the highest concentration $(0.52 \mathrm{~mol} / \mathrm{L})$ of both acetic and lactic acid. Inductively coupled plasma mass 
spectroscopy (ICP) was used to analyse the acid solution at the end of each exposure cycle (every week). This provided the concentration of metals such as $\mathrm{Al}, \mathrm{Ca}, \mathrm{Na}$ and $\mathrm{Si}$ that were leached from the specimens and found in each testing solution. At the end of 3 weeks, the paste samples were used for microstructural analysis. They were compared with control pastes which were submerged in water instead of acid but otherwise processed in the same way. Powdered samples were obtained by crushing and grinding the outside layer of the paste samples in a pestle and mortar. The powders were dried in a desiccator at $35{ }^{\circ} \mathrm{C}$ for $24 \mathrm{~h}$ prior to analysis. XRD was carried out with a PANalytical X'Pert PRO MPD diffractometer, applying CuK $\alpha$ radiation of wavelength $1.54 \AA$. Diffraction patterns were collected between 5 and $65^{\circ} 2 \theta$ with a step size of $0.02^{\circ}$. PANalytical X'Pert Highscore software with the powder diffraction file (PDF) database was used to analyse the diffraction patterns. Fourier transform infrared spectroscopy (FTIR) data was obtained using Jasco 4100 series FTIR Spectrometer with attenuated total reflectance attachment. The spectra were gathered between 650 and $2000 \mathrm{~cm}^{-1}$ wavenumber at $8 \mathrm{~cm}^{-1}$ resolution. Scanning electron microscopy (SEM) with elemental analysis was carried out on polished paste samples coated with gold. An accelerating voltage of $5 \mathrm{kV}$ and a working distance of $10 \mathrm{~mm}$ were used for imaging. The equipment used was QUANTA FEG250 with OXFORD X-Act as chemical composition analyser, which was run by Aztec version 2.0 software for analysis. Paste samples were sectioned and polished in preparation for SEM and elemental analysis.

\section{Results and discussion}

\section{Physical properties}

Fig. 4 shows photographs of each mortar mix after immersion in solutions of acetic and lactic acid for 8 weeks. Unexposed samples are also shown for comparison. Lactic acid appears to cause more damage to the surface of each mix compared with acetic acid. The alkali-activated mixes have suffered the loss of paste following immersion in the most concentrated lactic acid solutions and the loss of paste seems to have increased as the FA content increased. Following immersion in 0.31 and $0.52 \mathrm{~mol} / \mathrm{L}$ solutions of lactic acid, the OPC mix has also suffered the loss of cement paste, exposing sand particles. 
223 The mass change for each mix during 8 weeks of immersion in solutions of acetic and lactic acid is

224 shown in Fig. 5. For each mix the samples mass decreased with each consecutive week of immersion

225 in acid solutions. The lactic acid solutions caused larger mass losses than the acetic acid solutions for

226 each mix investigated. This is likely due to the higher dissociation constant of lactic acid compared

227 with acetic acid (Bertron and Duchesne 2013). As the concentration of acid increased the mass loss

228 also increased. In general the alkali-activated mortars displayed a rapid mass loss initially which

229 decelerated during each consecutive exposure cycle. Conversely the OPC mix displayed smaller mass

230 losses initially which accelerated with prolonged exposure, eventually having larger mass losses than

231 the alkali-activated mortars after 8 weeks. This was particularly the case when exposed to the higher

232 concentrations of each acid solution. The accelerating behaviour of the mass loss of the OPC mix is

233 likely due to the dissolution of phases causing an increase in porosity of the matrix allowing a faster

234 onset of further degradation. As the FA content increased the mass loss of the alkali-activated mortars

235 also increased following immersion in lactic acid. However, the opposite is true for acetic acid

236 immersion as shown in Fig. 6, but to a much lesser extent. The mass loss decreased as the FA content

237 increased. This suggests mixes with increased FA content are more resistant to acetic acid, but less

238 resistant to lactic acid. This phenomenon is discussed in more detail in the sections on leaching

239 behaviour and microstructural changes due to organic acid attack.

The compressive strength of each mix following immersion in solutions of acetic and lactic acid for 8 weeks is shown in Fig. 7. The compressive strength of unexposed samples (kept in water) are also shown for the comparison and the percentage strength loss values are also provided. Regardless of the acid concentration the strength loss was similar for the same mix and acid type. This could be because the strength loss is related to the acid penetration depth which may be similar regardless of acid concentration. As the FA content of the alkali-activated mixes increased their strength decreased. Following immersion in each acid the percentage strength loss values are between 31 and $47 \%$ for each mix and acid concentration investigated. Following immersion in lactic acid, FA/S-30/70 displayed the best performance with a strength loss of around $32 \%$. As the FA content increased the strength loss values also increased to values between 40 and $45 \%$. Comparing the effect of the two 
acid types on alkali-activated mortars shows that mixes with increased FA content (FA/S-80/20) had greater resistance to acetic whereas mixes with increased slag content had greater resistance to lactic acid. This agrees with the mass loss findings. The OPC mix experienced the largest strength losses following immersion in lactic acid of around $48 \%$.

Fig. 8 shows the cross-section of each mix after the application of phenolphthalein solution. Samples that were unexposed (kept in water) and immersed in $0.52 \mathrm{~mol} / \mathrm{L}$ solutions of acetic and lactic acid for 8 weeks are shown for comparison. The entire cross-section of the unexposed samples was coloured pink/purple, whereas the samples which were immersed in solutions of acetic and lactic acid have an outer layer which is not coloured indicating alkalinity loss. As the FA content increased the alkalinity loss also increased and can be related to the porosity and volume of voids of each mix which also increased as the FA content increased and is shown in Table 3. The increased porosity allows the acid solution to penetrate further, causing ion exchange and a loss of alkalinity. The alkalinity loss for OPC appeared similar to that of FA/S-30/70.

\section{Leaching behaviour}

Fig. 9 shows the $\mathrm{pH}$ of acetic and lactic acid solutions during immersion of mortar mixes for 8 weeks. At the beginning of each cycle the $\mathrm{pH}$ is low because the acid solution has been replenished with fresh acid. During each exposure cycle the $\mathrm{pH}$ increased as leaching occurred from the highly alkaline samples. For each acid type and concentration, the increase in $\mathrm{pH}$ was larger for OPC compared with the alkali-activated mortars. This indicates that the OPC mix has a higher acid neutralisation capacity than the alkali-activated mixes. This likely explains the smaller mass loss observed for OPC mixes compared with alkali-activated mixes exposed to the lowest concentration $(0.10 \mathrm{~mol} / \mathrm{L})$ of each acid used. During exposure to the higher concentrations of each acid the ability of OPC to neutralise the acid decreased. This likely explains the small mass losses initially which accelerated with increased exposure cycles (Fig. 5). For the alkali-activated mortars the mixes with increased FA content had less of a $\mathrm{pH}$ increase during each exposure cycle. This could indicate less leaching occurred. With an 
increased number of exposure cycles, the $\mathrm{pH}$ of the acid solutions decreased suggesting less leaching occurred with subsequent cycles.

Fig. 10 shows the cumulative concentrations of $\mathrm{Al}, \mathrm{Ca}, \mathrm{Na}$ and $\mathrm{Si}$ in solutions of water, acetic acid and lactic acid during immersion of alkali-activated and OPC paste mixes for 3 weeks. The main component leached into the acid solutions was Ca. The concentration was highest for OPC and decreased as the FA content increased in the alkali-activated pastes, likely due to the lower Ca content of FA compared with slag (Table 1). When organic acids interact with a cementitious matrix, various $\mathrm{Ca}$ and $\mathrm{Al}$ salt complexes are formed (Bertron and Duchesne 2013). The Ca concentrations found in the acid solutions were larger in acetic acid compared with lactic acid. This is likely due to the higher solubility of the Ca salt of acetic acid compared with the Ca salt of lactic acid meaning more Ca went into solution. On the other hand, the Al salt of lactic acid is more soluble than the Al salt of acetic acid (Bertron and Duchesne 2013). This explains the leaching of Al into the lactic acid solution. The concentration of $\mathrm{Al}$ in solution increased as the FA content increased (Fig. 10c). This is likely due to the increased $\mathrm{Al}$ content of FA compared with slag (Table 1). The amount of Na leached in the water and acid solutions was similar. In the case of $\mathrm{Si}$, only small quantities were found in the acid solutions, likely due to the preferential leaching of $\mathrm{Ca}$ and $\mathrm{Al}$ during acid attack.

Microstructural changes due to organic acid attack

The XRD pattern of each mix following immersion in $0.52 \mathrm{~mol} / \mathrm{L}$ solutions of acetic and lactic acid for 3 weeks is shown in Fig. 11. The patterns of unexposed (kept in water) samples are displayed as a reference. Mullite and quartz were identified in the unexposed alkali-activated mixes. These were present due to unreacted FA particles (Fig. 3) and the intensity of these peaks increased as the FA content increased. There was also a broad peak centred between 29 and $30^{\circ} 2 \theta$ and has been related to the presence of poorly crystalline calcium silicate hydrate (C-S-H) type gel by previous authors (Ben Haha et al. 2011; Wang and Scrivener 1995). Additionally, the peak assigned to quartz at around $50^{\circ}$ $2 \theta$ is broad in nature, likely due to the contribution of a broad peak at around $49.5^{\circ} 2 \theta$ indicating the presence of the same C-S-H type gel (Ben Haha et al. 2011). This may be calcium aluminium silicate 
hydrate (C-A-S-H) gel or calcium sodium aluminium silicate hydrate (C-N-A-S-H) gel, depending on the proportions and composition of FA and slag used (Aragón et al. 2020; Ismail et al. 2014). As the FA content increased, the intensity of this board peak between 29 and $30^{\circ} 2 \theta$ decreased, suggesting less C-S-H type gel was present. Following immersion in acid, this peak was no longer observed, indicating its decalcification or dealumination. This is confirmed by the presence of $\mathrm{Ca}$ and $\mathrm{Al}$ in the acid solution (Fig. 10). Additionally, following immersion in acid the broad hump centred between 15 and $35^{\circ} 2 \theta$ shifted left and was larger which indicated the formation of Si rich gels (Bernal et al. 2013; Provis et al. 2005; Shearer et al. 2016). This is in agreement with the limited Si found leached into the acid solutions and suggested that while $\mathrm{Ca}$ and $\mathrm{Al}$ were removed $\mathrm{Si}$ rich gels remained.

The main minerals identified in the unexposed OPC mix were calcium hydroxide and ettringite. Following immersion in acid these were no longer present due to their dissolution. Calcite was observed instead, similar to previous studies, and was likely formed due to the carbonation of calcium available following the dissolution of phases with high calcium content such as calcium hydroxide and ettringite (Beddoe and Dorner 2005; Bernal et al. 2012; Bertron et al. 2004). After exposure to lactic acid, calcium lactate hydrate was also observed in OPC. This is the Ca salt of lactic acid and is less soluble than the Ca salt of acetic acid (Bertron and Duchesne 2013). This explains why lactic acid resulted in less Ca being drawn into the acid solution than acetic acid (Fig. 10).

The FTIR spectra of each mix following immersion in $0.52 \mathrm{~mol} / \mathrm{L}$ solutions of acetic and lactic acid for 3 weeks is shown in Fig. 12. The patterns of unexposed (kept in water) samples are displayed as a reference. The band shown at around $1640 \mathrm{~cm}^{-1}$ in each sample was due to the bending mode of $\mathrm{H}-\mathrm{O}-$ H from water molecules (Burciaga-Díaz and Escalante-García 2012; Ismail et al. 2013). The main band in each alkali-activated mix which was not exposed to acid was found between 953 and $970 \mathrm{~cm}^{-}$ 1. This band is assigned to asymmetrical $\mathrm{T}-\mathrm{O}$ stretch vibrations $(\mathrm{T}=\mathrm{Si}$ or $\mathrm{Al})$ and indicates the presence of C-S-H type gel (García Lodeiro et al. 2009). Following acetic and lactic acid attack this main band shifts to higher wavenumbers between 1012 and $1045 \mathrm{~cm}^{-1}$. This indicates the decalcification and dealumination of C-S-H types gels such as C-A-S-H and C-N-A-S-H (Bascarevic 
et al. 2013; Bernal et al. 2012). A shoulder was also observed at around $1160 \mathrm{~cm}^{-1}$ which was identified as a Si rich gel product by previous authors (Bernal et al. 2012; García-Lodeiro et al. 2008). For each alkali-activated mix the main peak shifted less due to acetic acid attack (between 44 and 61 $\mathrm{cm}^{-1}$ ) than it did due to lactic acid attack (between 70 and $79 \mathrm{~cm}^{-1}$ ). This is likely due to the combination of decalcification and dealumination occurring due to lactic acid attack. In the case of acetic acid only decalcification occurred as evidenced by the leaching behaviour shown in Fig. 10. This is confirmed by FTIR as aluminosilicate gels which are centred at higher wavenumber have less Al present (Gu et al. 2020). The alkali-activated mixes which were attacked by acetic acid had their main band centred between 1012 and $1014 \mathrm{~cm}^{-1}$, while following lactic acid attack they were centred between 1032 and $1045 \mathrm{~cm}^{-1}$. This may explain the lower mass loss due to acetic acid as only decalcification occurred whereas lactic acid caused both decalcification and dealumination of the main binding gel and resulted in larger mass losses being observed (Fig. 6).

Following acetic and lactic acid attack the main band in OPC shifted from 960 to 1039 and $1030 \mathrm{~cm}^{-1}$, respectively. This indicated decalcification of C-S-H and like the alkali-activated mixes a shoulder was observed at around $1170 \mathrm{~cm}^{-1}$ which suggested the formation of Si rich gels. The band at 1105 $\mathrm{cm}^{-1}$, corresponding to ettringite was no longer observed after acid attack suggesting its decomposition (Bernal et al. 2012). Additional bands were observed at around 875 and $1425 \mathrm{~cm}^{-1}$ and have been attributed to the presence of calcite which was also observed by XRD (Bascarevic et al. 2013; Yu et al. 2004). An additional peak was also observed at around $1580 \mathrm{~cm}^{-1}$ following exposure to lactic acid and was previously related to carboxylic acid salts, in particular calcium lactate hydrate (National Institute of Standards and Technology 2018; Sedlarik et al. 2006; Song et al. 2014; Tian et al. 2015). This is in agreement with our XRD findings. Previous authors (De Belie et al. 1996; Singh et al. 1986) also observed the formation of calcium lactate hydrate following the interaction of calcium hydroxide and lactic acid.

SEM images of the outmost layer (approximately $2 \mathrm{~mm}$ ) of FA/S-30/70 and OPC paste mixes after immersion in lactic acid for 3 weeks are shown in Fig. 13. The distribution of $\mathrm{Al}, \mathrm{Ca}, \mathrm{Na}$ and $\mathrm{Si}$ is 
also shown and the arrow indicates the direction of acid attack. It was not possible to examine via

363 SEM all the combinations of mixes and acids investigated in this study. Therefore, one alkaliactivated mix (FA/S-30/70) and the OPC mix were examined following lactic acid attack as lactic acid was found to be more aggressive for both mixes. FA/S-30/70 has two distinct layers visible. The outer layer (1) which is darker in colour and has cracks and voids where alkali-activated paste has been removed. The inner layer (2) is lighter in colour and appears more intact with the exception of a few large cracks. The elemental analysis shows that the outer layer (1) has suffered depletion of Al and $\mathrm{Ca}$, while the concentration of $\mathrm{Na}$ and $\mathrm{Si}$ appears to have increased in the outer layer. This is in agreement with the leaching behaviour observed and the results obtained by XRD and FTIR. It appears the C-A-S-H type gel present suffered decalcification and dealumination resulting in a relatively thick layer of Si rich gel which also contained $\mathrm{Na}$.

The OPC mix appeared to have three main layers. The outer layer (1) appears very porous and has suffered a significant depletion of $\mathrm{Ca}$. This is in agreement with the decomposition of calcium hydroxide and ettringite observed by XRD and FTIR following acid attack and the leaching of Ca into solution (Fig. 10). Similar to FA/S-30/70, the concentration of Si appears to have increased in the outer layer (1). The second layer (2) contains several cracks parallel to the outer surface and has suffered some depletion of Ca. This suggests that the outer layer (1) of Si rich gel has not been able to resist further acid attack. The innermost layer (3) appears intact and unaffected by acid attack.

In OPC the outer layer appears more porous than the outer layer in FA/S-30/70. This is likely due to the vulnerability of phases such as calcium hydroxide and ettringite which are not present in FA/S30/70. Therefore, the outer layer of FA/S-30/70 is more dense and able to resist further acid attack. This is evidenced by the slightly decalcified second layer (2) of paste observed in OPC which is not observed in FA/S-30/70. Furthermore, the mass losses for OPC are accelerating but are decelerating for FA/S-30/70 (Fig. 5). This can be related to the more dense Si gel observed in the outer layer of FA/S-30/70. 


\section{Conclusion}

391 The following conclusions have been drawn from this study.

- Alkali-activated mixes with increased FA content had similar or better resistance to acetic

413 This study suggests alkali-activated FA/slag binders have the potential to provide increased service 414 life for concrete structures exposed to organic acids in the agri-food industries. Findings also indicate 415 that the type of organic acid should dictate the composition of alkali-activated binder which is most 


\section{Data availability statement}

419 All data, models, and code generated or used during the study appear in the submitted article.

\section{Acknowledgements}

The authors would like to acknowledge the facilities provided by the School of Natural and Built Environment, Queen's University Belfast. The research studentship provided by the Department of Finance, Northern Ireland is also gratefully acknowledged. The authors also appreciate the support received and useful discussions had with Prof. Marios Soutsos.

\section{References}

Aiken, T. A. (2017). "Durability of geopolymer materials in aggressive aqueous environments - acid attack, steel reinforcement corrosion and freeze-thaw attack." Queen's University Belfast, PhD thesis.

Aiken, T. A., Kwasny, J., Sha, W., and Soutsos, M. N. (2018). "Effect of slag content and activator dosage on the resistance of fly ash geopolymer binders to sulfuric acid attack." Cement and Concrete Research, 111, 23-40.

Aiken, T. A., Sha, W., Kwasny, J., and Soutsos, M. N. (2017). "Resistance of geopolymer and Portland cement based systems to silage effluent attack." Cement and Concrete Research, 92, $56-65$.

Allahverdi, A., and Škvára, F. (2001). "Nitric acid attack on hardened paste of geopolymeric cements Part 1." Ceramics, 45(3), 81-88.

Allahverdi, A., and Škvára, F. (2005). "Sulfuric acid attack on hardened paste of geopolymer cements Part 1. Mechanism of corrosion at relatively high concentrations." Ceramics, 49(4), 225-229.

American Society for Testing and Materials. (2006). ASTM C642 Standard test method for density, absorption and voids in hardened concrete. West Conshohocken, USA.

American Society for Testing and Materials. (2012). ASTM C267 - 01(2012) Standard test methods for chemcial resistance of mortars, grouts, and monolithic surfacings and polymer concretes. 
Aragón, P., Robayo-Salazar, R. A., and Mejía de Gutiérrez, R. (2020). "Alkali-activated concrete based on natural volcanic pozzolan: chemical resistance to sulfate attack." Journal of Materials in Civil Engineering, 32(5), 4020106.

Bakharev, T. (2005). "Geopolymeric materials prepared using Class F fly ash and elevated temperature curing." Cement and Concrete Research, 35(6), 1224-1232.

Bascarevic, Z., Komljenovic, M., Miladinovic, Z., Nikolic, V., Marjanovic, N., Zujovic, Z., and Petrovic, R. (2013). "Effects of the concentrated $\mathrm{NH}_{4} \mathrm{NO}_{3}$ solution on mechanical properties and structure of the fly ash based geopolymers." Construction and Building Materials, 41(3), 570579.

Beddoe, R. E., and Dorner, H. W. (2005). "Modelling acid attack on concrete: Part I. The essential mechanisms." Cement and Concrete Research, 35, 2333-2339.

De Belie, N., Debruyckere, M., Van Nieuwenburg, D., and De Blaere, B. (1997). “Attack of concrete floors in pig houses by feed acids: Influence of fly ash addition and cement-bound surface layers.” Journal of Agricultural Engineering Research, 68, 101-108.

De Belie, N., Verselder, H. J., De Blaere, B., Van Nieuwenburg, D., and Verschoore, R. (1996). "Influence of the cement type on the resistance of concrete to feed acids." Cement and Concrete Research, 26(11), 1717-1725.

Bernal, S. A., Provis, J. L., Walkley, B., San Nicolas, R., Gehman, J. D., Brice, D. G., Kilcullen, A. R., Duxson, P., and van Deventer, J. S. J. (2013). "Gel nanostructure in alkali-activated binders based on slag and fly ash, and effects of accelerated carbonation." Cement and Concrete Research, 53, 127-144.

Bernal, S. A., Rodríguez, E. D., de Gutierrez, R. M., and Provis, J. L. (2012). "Performance of alkaliactivated slag mortars exposed to acids.” Journal of Sustainable Cement-Based Materials, 1, $37-41$.

Bertron, A. (2013). "Methods for testing cementitious materials exposed to organic acids." Performance of Cement-Based Materials in Aggressive Aqueous Environments, M. Alexander, A. Bertron, and N. De Belie, eds., Springer, Dordrecht, Germany, 355-387.

Bertron, A., and Duchesne, J. (2013). "Attack of cementitious materials by organic acids in 
agricultural and agrofood effluents." Performance of Cement-Based Materials in Aggressive Aqueous Environments, M. Alexander, A. Bertron, and N. De Belie, eds., Springer, Dordrecht, Germany, 131-173.

Bertron, A., Duchesne, J., and Escadeillas, G. (2005a). “Accelerated tests of hardened cement pastes alteration by organic acids: analysis of the $\mathrm{pH}$ effect." Cement and Concrete Research, 35, 155166.

Bertron, A., Duchesne, J., and Escadeillas, G. (2005b). "Attack of cement pastes exposed to organic acids in manure." Cement and Concrete Composites, 27, 898-909.

Bertron, A., Escadeillas, G., and Duchesne, J. (2004). "Cement pastes alteration by liquid manure organic acids: Chemical and mineralogical characterization." Cement and Concrete Research, $34,1823-1835$.

British Standards Institution. (1995). BS 812-2:1995 Testing aggregates. Methods for determination of density. London, UK.

British Standards Institution. (2006). BS EN 15167-1:2006 - Ground granulated blast furnace slag for use in concrete, mortar and grout. Definitions, specifications and conformity criteria. London, UK.

British Standards Institution. (2011). BS EN 197-1:2011 Cement Part 1: Composition, specifications and conformity criteria for common cements. London, UK.

British Standards Institution. (2012). BS EN 450-1:2012 - Fly ash for concrete. Definition, specifications and conformity criteria. London, UK.

Burciaga-Díaz, O., and Escalante-García, J. I. (2012). "Strength and durability in acid media of alkali silicate-activated metakaolin geopolymers." Journal of the American Ceramic Society, 95(7), 2307-2313.

Castillo Lara, R., and Chagas Cordeiro, G. (2019). "Effect of Rice Husk Ash as Supplementary Cementitious Material on the Performance of Cement-Based Pastes Continuously Exposed to Organic Acid Solution (Vinasse)." Journal of Materials in Civil Engineering, 31(7), 1-10.

Chang, C.-F., and Chen, J.-W. (2006). "The experimental investigation of concrete carbonation depth." Cement and Concrete Research, 36(9), 1760-1767. 
Chinchón-Payá, S., Andrade, C., and Chinchón, S. (2016). "Indicator of carbonation front in concrete as substitute to phenolphthalein." Cement and Concrete Research, 82, 87-91.

Collins, F. G., and Sanjayan, J. G. (1999). "Workability and mechanical properties of alkali activated slag concrete." Cement and Concrete Research, 29(3), 455-458.

El-Hassan, H., and Elkholy, S. (2019). "Performance Evaluation and Microstructure Characterization of Steel Fiber-Reinforced Alkali-Activated Slag Concrete Incorporating Fly Ash.” Journal of Materials in Civil Engineering, 31(10), 1-16.

García-Lodeiro, I., Fernández-Jiménez, A., Blanco, M. T., and Palomo, A. (2008). "FTIR study of the sol-gel synthesis of cementitious gels: C-S-H and N-A-S-H.” Journal of Sol-Gel Science and Technology, 45, 63-72.

García Lodeiro, I., Macphee, D. E., Palomo, A., and Fernández-Jiménez, A. (2009). "Effect of alkalis on fresh C-S-H gels. FTIR analysis.” Cement and Concrete Research, 39, 147-153.

Gruyaert, E., Van Den Heede, P., Maes, M., and De Belie, N. (2012). "Investigation of the influence of blast-furnace slag on the resistance of concrete against organic acid or sulphate attack by means of accelerated degradation tests." Cement and Concrete Research, 42(1), 173-185.

Gu, L., Visintin, P., and Bennett, T. (2020). "Sulphuric Acid Resistance of Cementitious Materials: Multiscale Approach to Assessing the Degradation.” Journal of Materials in Civil Engineering, 32(7), 04020171.

Ben Haha, M., Le Saout, G., Winnefeld, F., and Lothenbach, B. (2011). "Influence of activator type on hydration kinetics, hydrate assemblage and microstructural development of alkali activated blast-furnace slags." Cement and Concrete Research, 41, 301-310.

Ismail, I., Bernal, S. A., Provis, J. L., Hamdan, S., and Van Deventer, J. S. J. (2013). "Drying-induced changes in the structure of alkali-activated pastes." Journal of Materials Science, 48, 35663577.

Ismail, I., Bernal, S. A., Provis, J. L., San Nicolas, R., Hamdan, S., and Van Deventer, J. S. J. (2014). "Modification of phase evolution in alkali-activated blast furnace slag by the incorporation of fly ash." Cement and Concrete Composites, 45, 125-135.

Kwasny, J., Aiken, T. A., Soutsos, M. N., Cleland, D. J., and Mcintosh, J. A. (2018a). “Comparison of 
lithomarge and cement-based mortars performance in aggressive aqueous environments." International Conference on the Durability of Concrete Structures, Leeds, UK.

Kwasny, J., Aiken, T. A., Soutsos, M. N., Mcintosh, J. A., and Cleland, D. J. (2018b). "Sulfate and acid resistance of lithomarge-based geopolymer mortars." Construction and Building Materials, 166, 537-553.

Kwasny, J., Soutsos, M. N., McIntosh, J. A., and Cleland, D. J. (2018c). "Comparison of the effect of mix proportion parameters on behaviour of geopolymer and Portland cement mortars." Construction and Building Materials, 187, 635-651.

Lee, N. K., and Lee, H. K. (2016). "Influence of the slag content on the chloride and sulfuric acid resistances of alkali-activated fly ash / slag paste." Cement and Concrete Composites, 72, 168179.

Liu, E., Ghandehari, M., Brückner, C., Khalil, G., Worlinsky, J., Jin, W., Sidelev, A., and Hyland, M. A. (2017). "Mapping high pH levels in hydrated calcium silicates." Cement and Concrete Research, 95, 232-239.

Lloyd, R. R., Provis, J. L., and van Deventer, J. S. J. (2012). “Acid resistance of inorganic polymer binders. 1. Corrosion rate." Materials and Structures, 45(1-2), 1-14.

Nath, P., and Sarker, P. K. (2014). "Effect of GGBFS on setting, workability and early strength properties of fly ash geopolymer concrete cured in ambient condition." Construction and Building Materials, 66, 163-171.

National Institute of Standards and Technology. (2018). "Calcium lactate." NIST Chemistry Webbook, SRD69, <https://webbook.nist.gov/cgi/cbook.cgi?ID=C5743475\&Mask=80\#IR-Spec> (Apr. 22, 2020).

Provis, J. L., Lukey, G. C., and van Deventer, J. S. J. (2005). “Do Geopolymers Actually Contain Nanocrystalline Zeolites? A Reexamination of Existing Results.” Chemistry of Materials, American Chemical Society, 17(12), 3075-3085.

Rafeet, A., Vinai, R., Soutsos, M., and Sha, W. (2017). "Guidelines for mix proportioning of fly ash/GGBS based alkali activated concretes." Construction and Building Materials, 147, 130142. 
Rafeet, A., Vinai, R., Soutsos, M., and Sha, W. (2019). "Effects of slag substitution on physical and mechanical properties of fly ash-based alkali activated binders (AABs)." Cement and Concrete Research, 122, 118-135.

Rakhimova, N. R., and Rakhimov, R. Z. (2019). "Literature review of advances in materials used in development of alkali-activated mortars, concretes, and composites." Journal of Materials in Civil Engineering, 31(11), 3119002.

Sedlarik, V., Saha, N., Kuritka, I., Emri, I., and Saha, P. (2006). "Modification of poly(vinyl alcohol) with lactose and calcium lactate: Potential filler from dairy industry." Plastics, Rubber and Composites, 35(9), 355-359.

Shearer, C. R., Provis, J. L., Bernal, S. A., and Kurtis, K. E. (2016). "Alkali-activation potential of biomass-coal co-fired fly ash." Cement and Concrete Composites, 73, 62-74.

Shi, C., Qu, B., and Provis, J. L. (2019). "Recent progress in low-carbon binders." Cement and Concrete Research, 122, 227-250.

Shi, C., and Stegemann, J. A. (2000). "Acid corrosion resistance of different cementing materials." Cement and Concrete Research, 30(5), 803-808.

Singh, N. B., Prabha, S., and Singh, A. K. (1986). "Effect of lactic acid on the hydration of portland cement." Cement and Concrete Research, 16(4), 545-553.

Song, X., Wang, H., Yang, X., Liu, F., Yu, S., and Liu, S. (2014). "Hydrolysis of poly(lactic acid) into calcium lactate using ionic liquid $[\mathrm{Bmim}][\mathrm{OAc}]$ for chemical recycling." Polymer Degradation and Stability, 110, 65-70.

Tian, S., Hou, Y., Wu, W., Ren, S., Wang, C., and Qian, J. (2015). "Reversible absorption of SO2 from simulated flue gas by aqueous calcium lactate solution." Journal of the Taiwan Institute of Chemical Engineers, Elsevier Ltd., 54, 71-75.

Vinai, R., Rafeet, A., Soutsos, M., and Sha, W. (2016). "The role of water content and paste proportion on physico-mechanical properties of alkali activated fly ash - ggbs concrete.” Journal of Sustainable Metallurgy, 2, 51-61.

Wang, S. D., and Scrivener, K. L. (1995). "Hydration products of alkali activated slag cement." Cement and Concrete Research, 25(3), 561-571. 


\begin{tabular}{lccc}
\hline Oxide composition (\%) & FA & Slag & Portland cement \\
\hline $\mathrm{SiO}_{2}$ & 46.78 & 29.38 & 20.21 \\
$\mathrm{Al}_{2} \mathrm{O}_{3}$ & 22.52 & 11.23 & 4.79 \\
$\mathrm{Fe}_{2} \mathrm{O}_{3}$ & 9.15 & 0.36 & 2.78 \\
$\mathrm{CaO}$ & 2.24 & 43.72 & 63.01 \\
$\mathrm{MgO}$ & 1.33 & 6.94 & 1.93 \\
$\mathrm{MnO}$ & 0.05 & 0.51 & 0.08 \\
$\mathrm{TiO}_{2}$ & 1.05 & 0.67 & 0.27 \\
$\mathrm{Na}_{2} \mathrm{O}$ & 0.89 & 1.05 & 0.19 \\
$\mathrm{~K}_{2} \mathrm{O}$ & 4.09 & 0.93 & 0.59 \\
$\mathrm{SO}_{3}$ & 0.90 & 1.76 & 2.60 \\
\hline $\mathrm{LOI}(\%)$ & 3.57 & 2.40 & 3.16 \\
\hline Specific gravity & 2.42 & 2.92 & 3.13 \\
\hline
\end{tabular}
Ceramic Society, 82(3), 742-748.

\section{Tables}

592 Table 2. Mix proportions $\left(\mathrm{kg} / \mathrm{m}^{3}\right)$ for alkali-activated and ordinary Portland cement mortars

\begin{tabular}{|c|c|c|c|c|c|}
\hline \multicolumn{2}{|c|}{ Mix composition } & FA/S-30/70 & FA/S-60/40 & FA/S-80/20 & OPC \\
\hline \multirow{3}{*}{$\begin{array}{l}\text { Binder } \\
\text { composition }\end{array}$} & Fly ash (\%) & 30 & 60 & 80 & - \\
\hline & Slag $(\%)$ & 70 & 40 & 20 & - \\
\hline & OPC $(\%)$ & - & - & - & 100 \\
\hline \multicolumn{2}{|c|}{ Paste content (vol. \%) } & 50 & 50 & 50 & 50 \\
\hline \multicolumn{2}{|c|}{ Water/solid ratio } & 0.42 & 0.40 & 0.38 & - \\
\hline \multicolumn{2}{|c|}{ Water/cement ratio } & - & - & - & 0.42 \\
\hline \multicolumn{2}{|c|}{ Alkali dosage $(\mathrm{M}+)$} & 7.5 & 7.5 & 7.5 & - \\
\hline \multicolumn{2}{|l|}{$\mathrm{Na}_{2} \mathrm{O} / \mathrm{SiO}_{2}$} & 1.25 & 1.25 & 1.25 & - \\
\hline \multicolumn{2}{|c|}{ Fly ash $\left(\mathrm{kg} / \mathrm{m}^{3}\right)$} & 172 & 344 & 463 & - \\
\hline \multicolumn{2}{|c|}{ Slag $\left(\mathrm{kg} / \mathrm{m}^{3}\right)$} & 401 & 229 & 116 & - \\
\hline \multicolumn{2}{|c|}{ Portland cement $\left(\mathrm{kg} / \mathrm{m}^{3}\right)$} & - & - & - & 676 \\
\hline \multicolumn{2}{|c|}{ Sodium silicate $\left(\mathrm{kg} / \mathrm{m}^{3}\right)$} & 135 & 135 & 136 & - \\
\hline \multicolumn{2}{|c|}{ Sodium hydroxide $\left(\mathrm{kg} / \mathrm{m}^{3}\right)$} & 111 & 111 & 112 & - \\
\hline \multicolumn{2}{|c|}{ Sand $\left(\mathrm{kg} / \mathrm{m}^{3}\right)$} & 1348 & 1348 & 1348 & 1348 \\
\hline \multicolumn{2}{|c|}{ Absorption water $\left(\mathrm{kg} / \mathrm{m}^{3}\right)$} & 12 & 12 & 12 & 12 \\
\hline \multicolumn{2}{|c|}{ Total added water $\left(\mathrm{kg} / \mathrm{m}^{3}\right)$} & 125 & 112 & 100 & 296 \\
\hline
\end{tabular}

593

Yu, P., Kirkpatrick, R. J., Poe, B., McMillan, P. F., and Cong, X. (2004). "Structure of calcium silicate hydrate (C-S-H): near-, mid-, and far-infrared spectroscopy.” Journal of the American

Table 1. Oxide composition and loss on ignition (LOI) of FA, slag and Portland cement.

$594 \quad$ Table 3. Porosity and volume of permeable voids for each mortar mix at 28 days.

\begin{tabular}{lcc}
\hline Mix & Porosity $(\%)$ & VPV $(\%)$ \\
\hline FA/S-30/70 & 5.3 & 8.5 \\
FA/S-60/40 & 11.5 & 12.3 \\
FA/S-80/20 & 15.8 & 19.0 \\
OPC & 10.1 & 12.5 \\
\hline
\end{tabular}


597 Fig. 1. Photograph of a) grass stored in a concrete silo with brown effluent leaching out and b) 598 damage to a concrete floor caused by silage effluent.

599 Fig. 2. Particle size distribution of fly ash, slag, Portland cement and sand.

600 Fig. 3. XRD patterns of FA, slag and Portland cement.

601 Fig. 4. Photographs of each mortar mix after immersion in solutions of acetic and lactic acid for 8 602 weeks.

603 Fig. 5. Mass change of a) FA/S-30/70, b) FA/S-60/40, c) FA/S-80/20 and d) OPC following 604 immersion in solutions of acetic and lactic acid for 8 weeks.

605 Fig. 6. Mass change of alkali activated mortars following immersion in solutions of acetic and lactic 606 acid for 8 weeks.

607 Fig. 7. Compressive strength of alkali-activated and OPC mortars following immersion in solutions of 608 a) acetic and b) lactic acid for 8 weeks. The percentage compressive strength loss values are also 609 provided.

610 Fig. 8. Cross-sections of alkali-activated and OPC mortar mixes after application of phenolphthalein 611 solution following immersion in water (unexposed) and $0.52 \mathrm{~mol} / \mathrm{L}$ solutions of acetic and lactic acid.

612 Fig. 9. $\mathrm{pH}$ of acetic and lactic acid solutions during immersion of mortar mixes for 8 weeks.

613 Fig. 10. Cumulative concentration of $\mathrm{Al}, \mathrm{Ca}, \mathrm{Na}$ and $\mathrm{Si}$ in solutions of water, acetic acid and lactic 614 acid during immersion of alkali-activated and OPC paste mixes for 3 weeks.

615 Fig. 11. XRD patterns of each paste mix after immersion in solutions of acetic and lactic acid for 3 616 weeks.

617 Fig. 12. FTIR spectra of each paste mix after immersion in solutions of acetic and lactic acid for 3 618 weeks.

619 Fig. 13. SEM images and elemental analysis of the outmost layer of a) FA/S-30/70 and b) OPC paste 620 mixes after immersion in lactic acid for 3 weeks. 


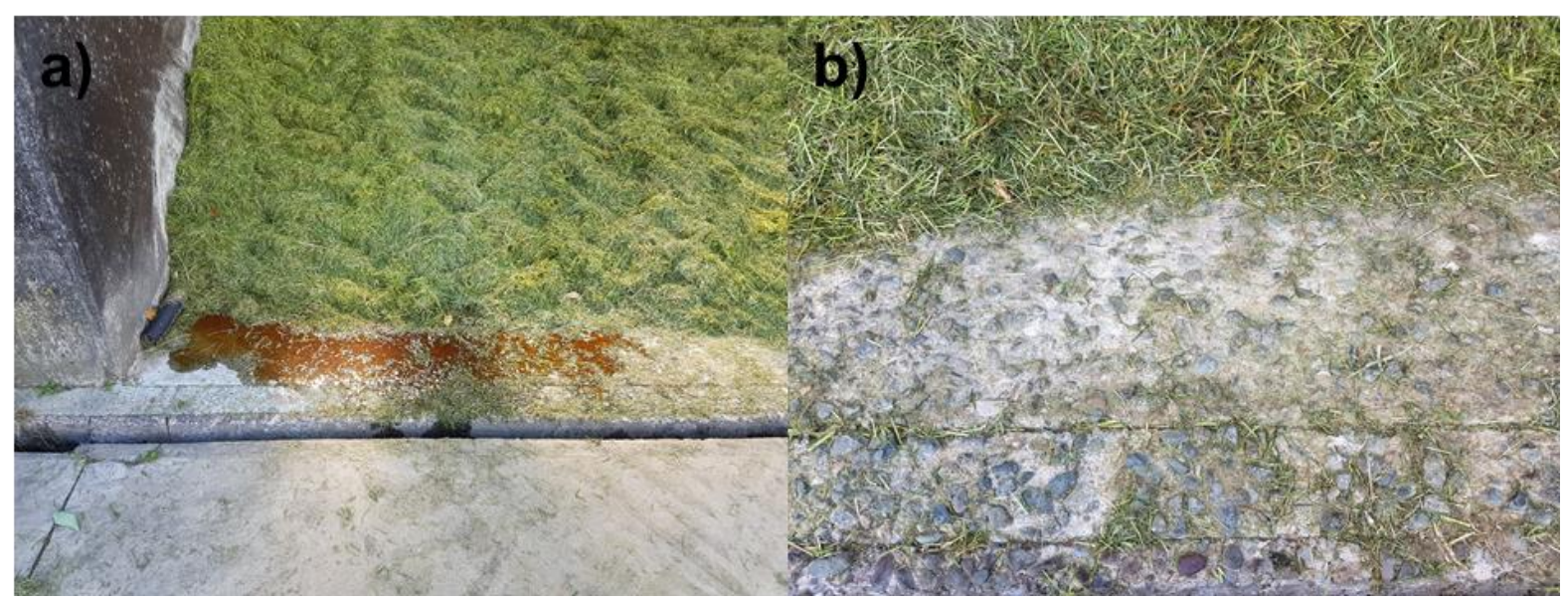

624 Fig. 1. Photograph of a) grass stored in a concrete silo with brown effluent leaching out and b) 625 damage to a concrete floor caused by silage effluent.

626

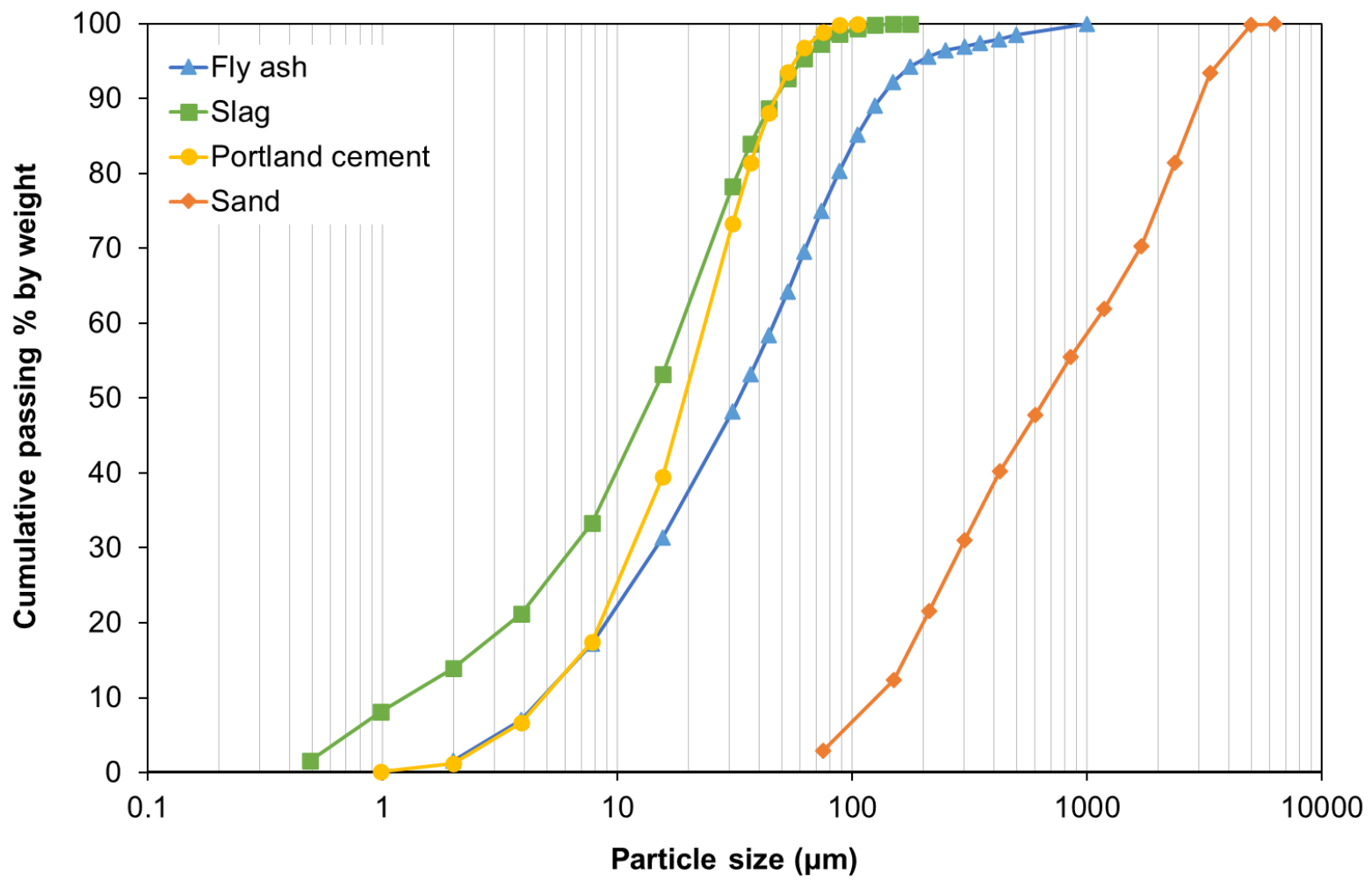

627

628 Fig. 2. Particle size distribution of fly ash, slag, Portland cement and sand. 


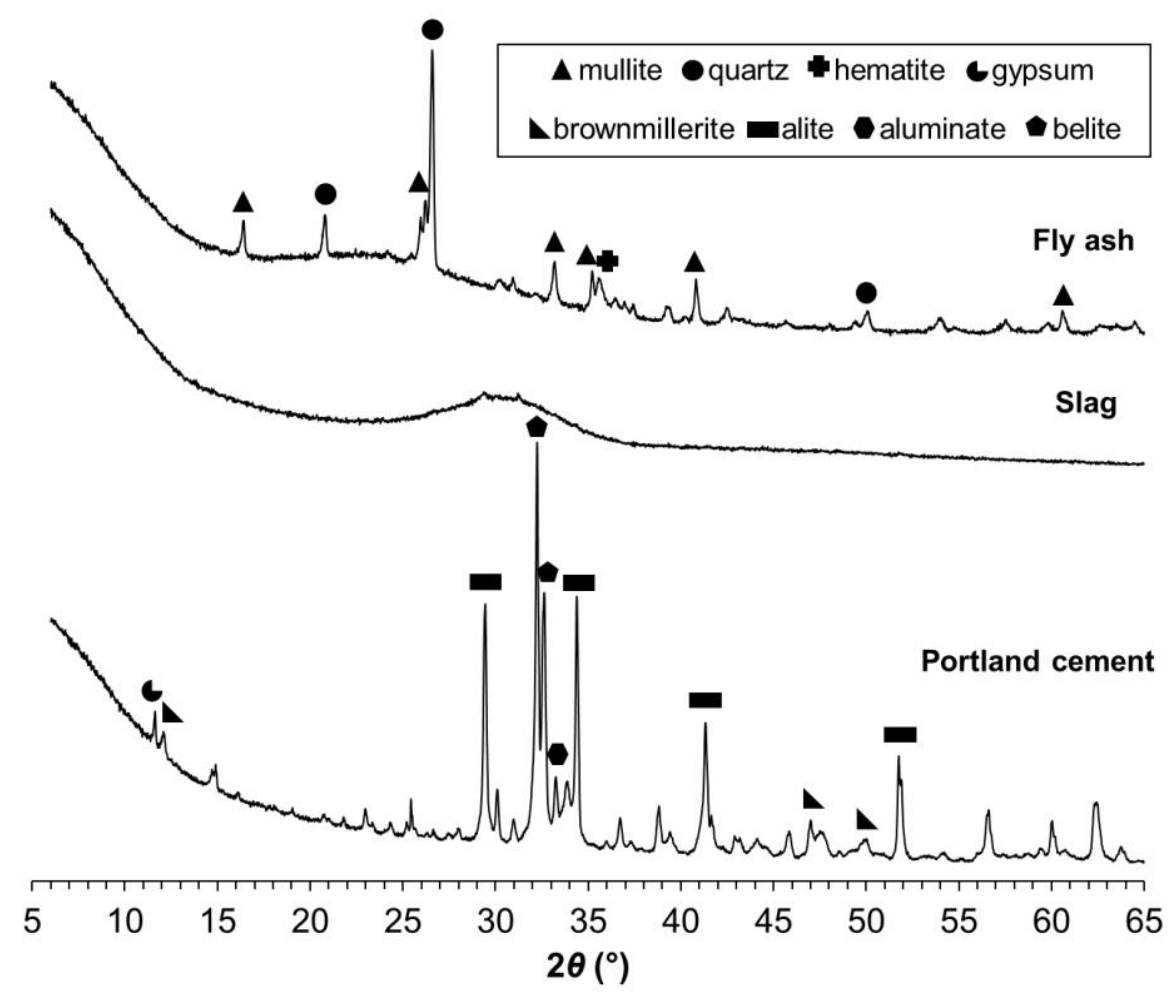

631 Fig. 3. XRD patterns of FA, slag and Portland cement.

632

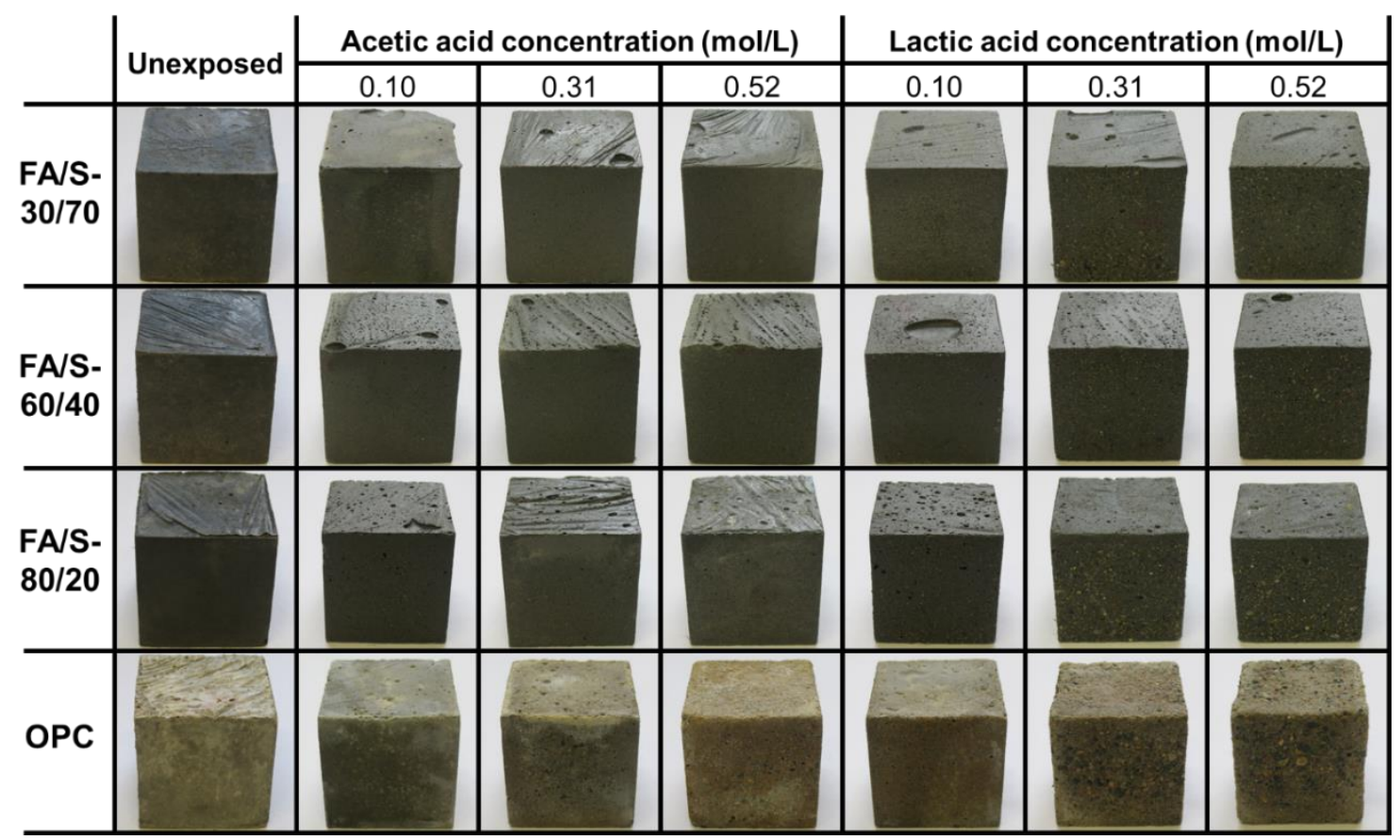

634 Fig. 4. Photographs of each mortar mix after immersion in solutions of acetic and lactic acid for 8 635 weeks. 

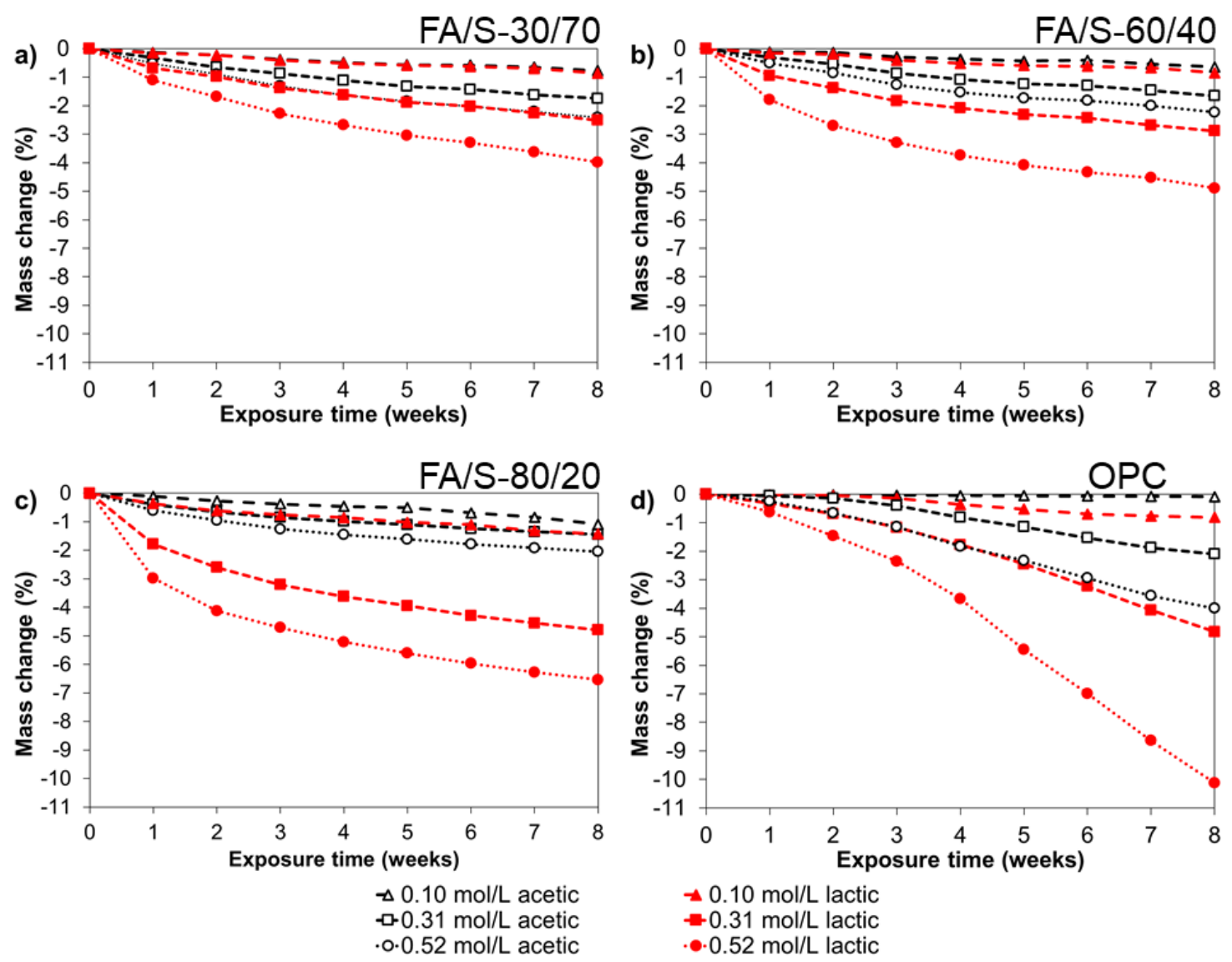

Fig. 5. Mass change of a) $F A / S-30 / 70$,

b) FA/S-60/40,

c) FA/S-80/20 and d) OPC following immersion in solutions of acetic and lactic acid for 8 weeks.

639

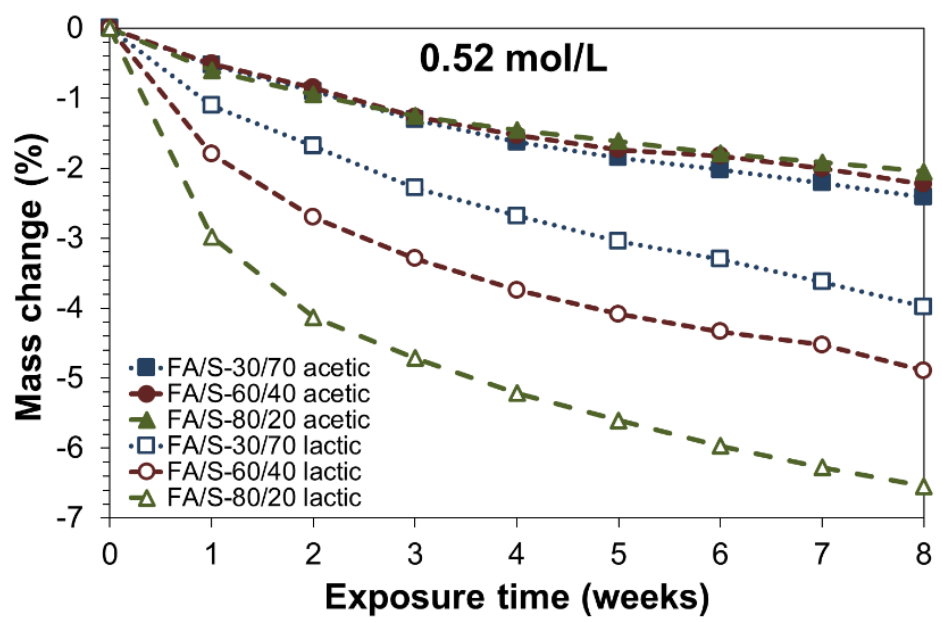

641 Fig. 6. Mass change of alkali activated mortars following immersion in solutions of acetic and lactic acid for 8 weeks. 

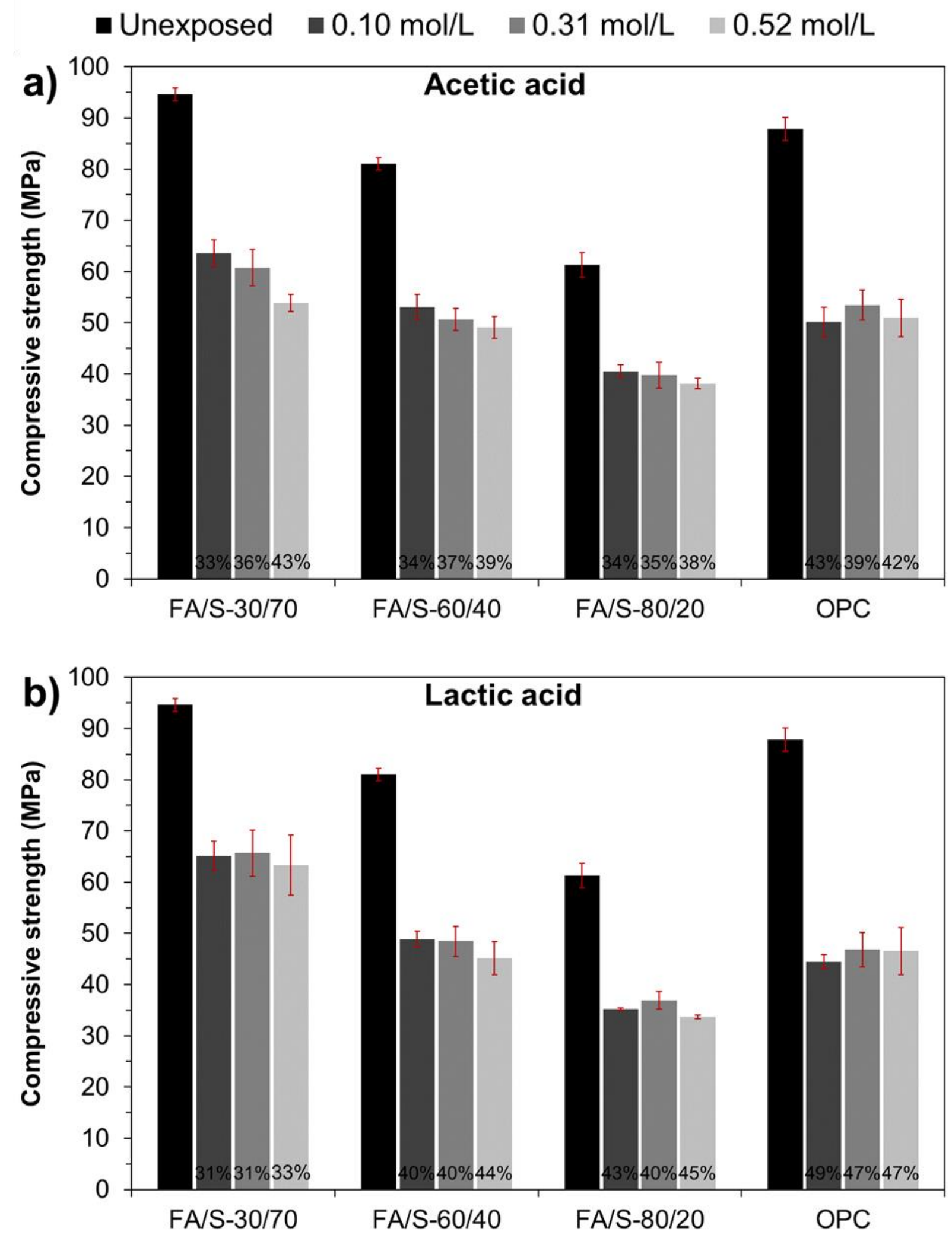

644 Fig. 7. Compressive strength of alkali-activated and OPC mortars following immersion in solutions of

645 a) acetic and b) lactic acid for 8 weeks. The percentage compressive strength loss values are also 646 provided. 


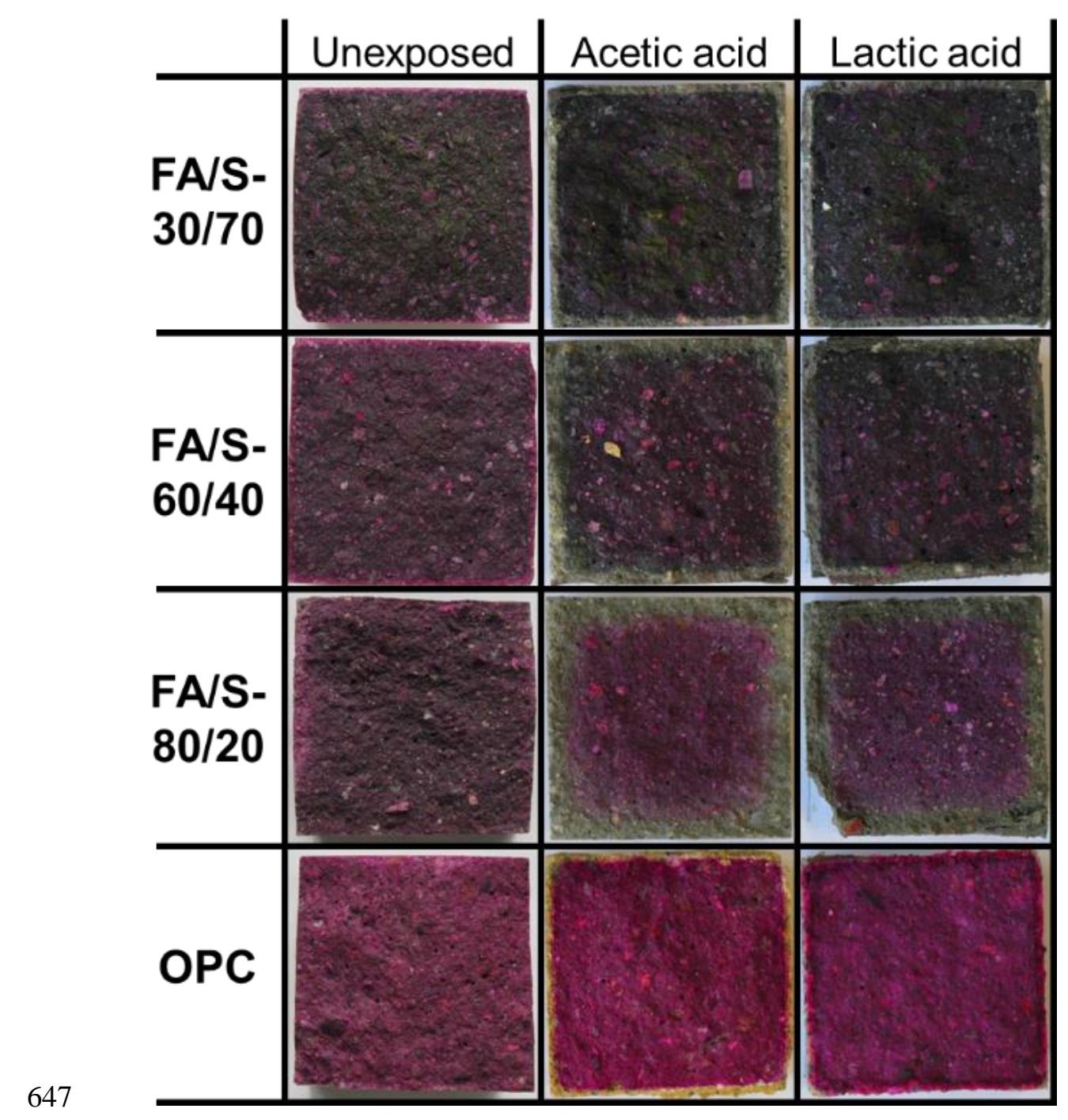

648 Fig. 8. Cross-sections of alkali-activated and OPC mortar mixes after application of phenolphthalein 649 solution following immersion in water (unexposed) and $0.52 \mathrm{~mol} / \mathrm{L}$ solutions of acetic and lactic acid. 

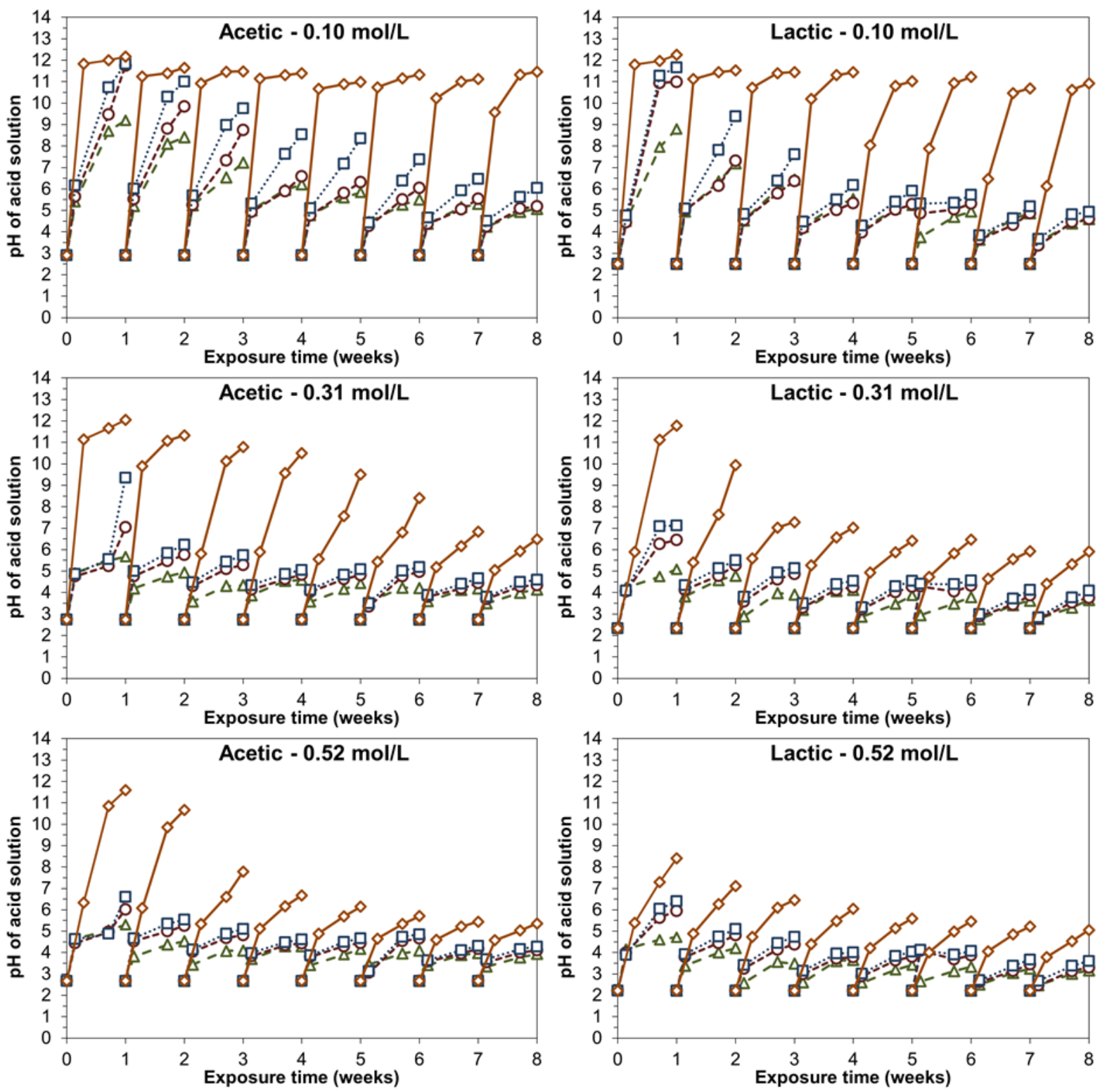

650

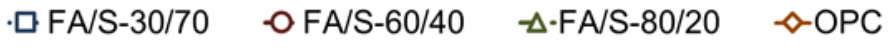

651 Fig. 9. $\mathrm{pH}$ of acetic and lactic acid solutions during immersion of mortar mixes for 8 weeks. 

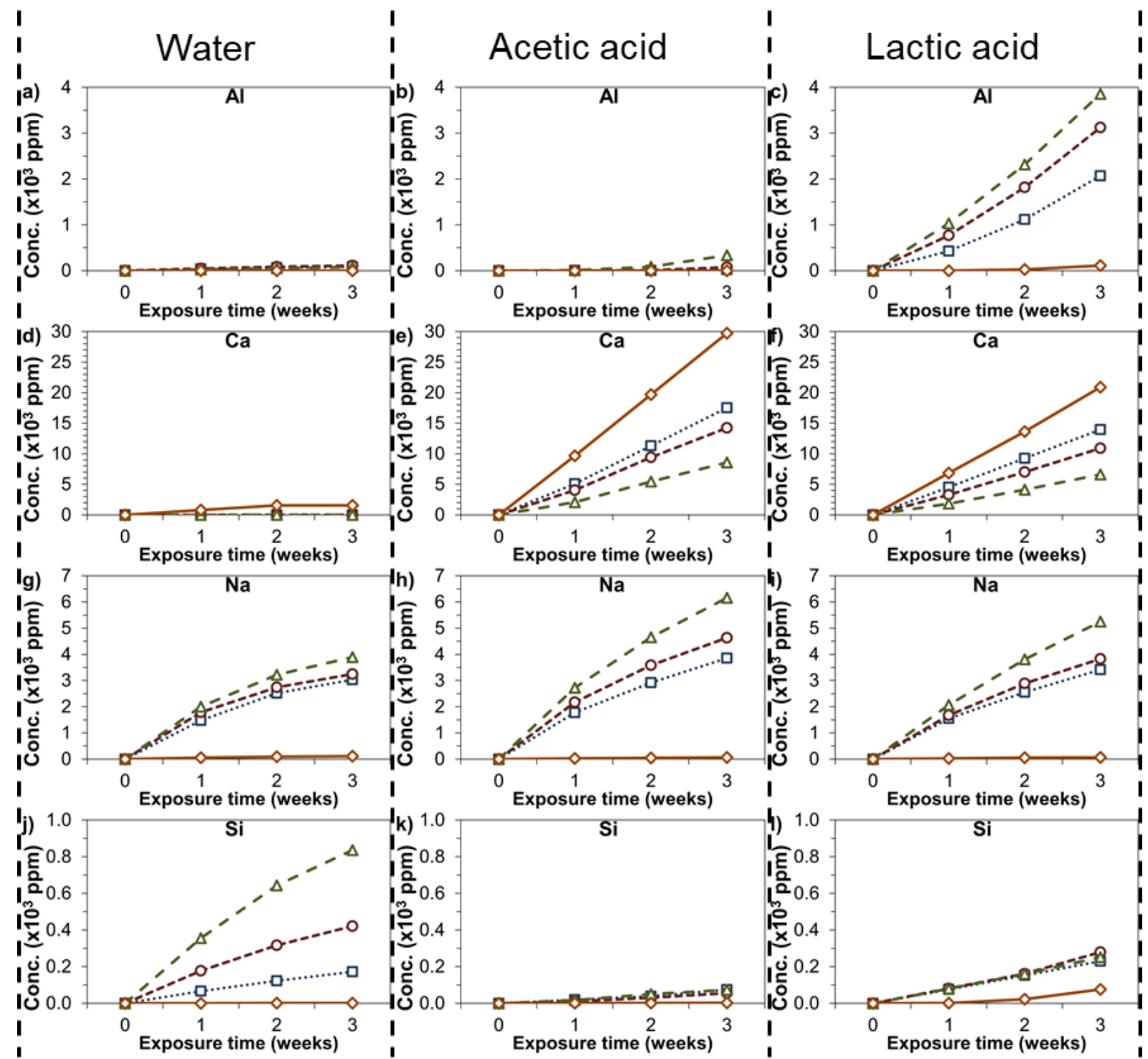

653 Fig. 10. Cumulative concentration of $\mathrm{Al}, \mathrm{Ca}, \mathrm{Na}$ and $\mathrm{Si}$ in solutions of water, acetic acid and lactic acid during immersion of alkali-activated and OPC paste mixes for 3 weeks. 
$\Delta$ mullite quartz $\Delta$ calcite $\square$ calcium hydroxide $\diamond$ ettringite Ocalcium lactate hydrate
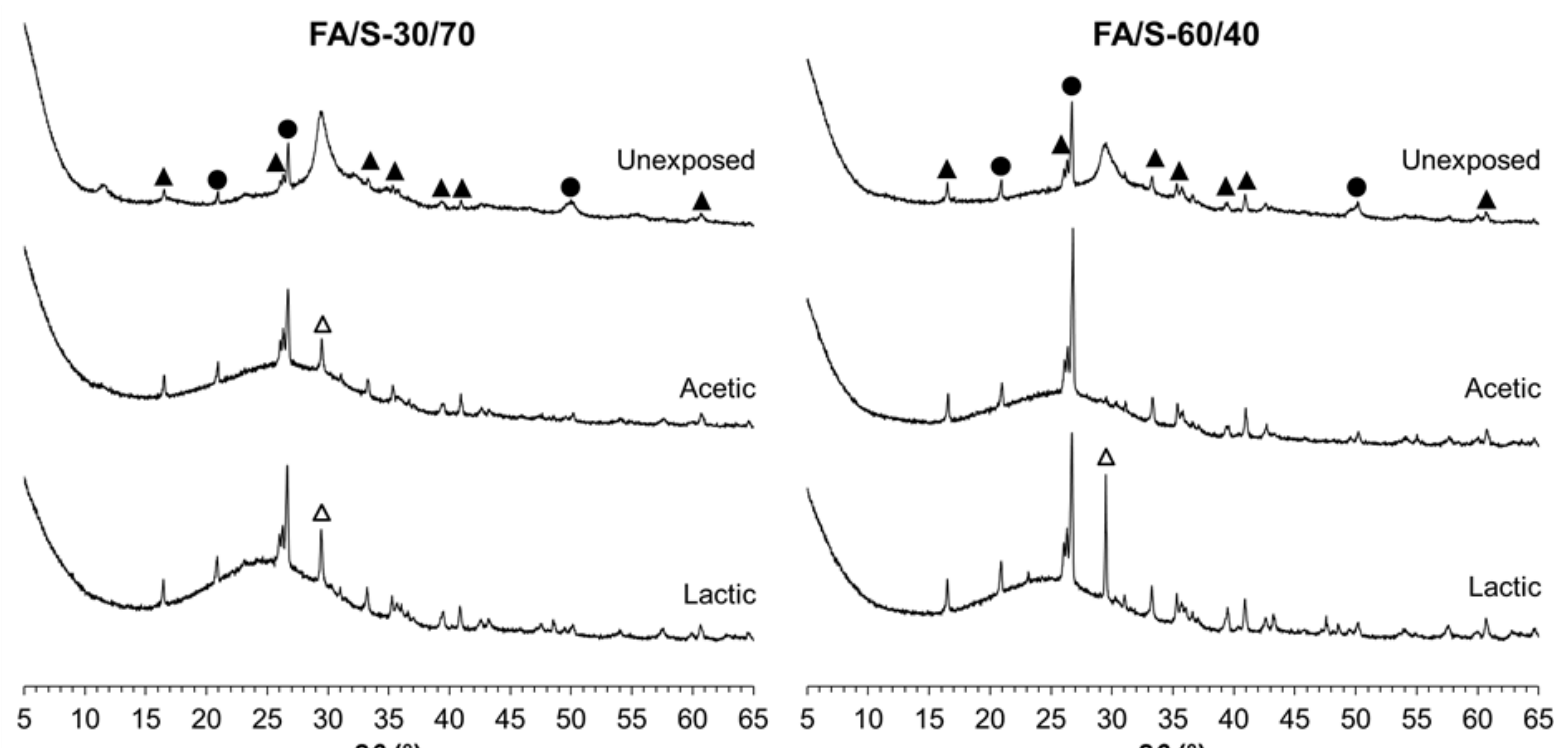
$2 \theta\left({ }^{\circ}\right)$
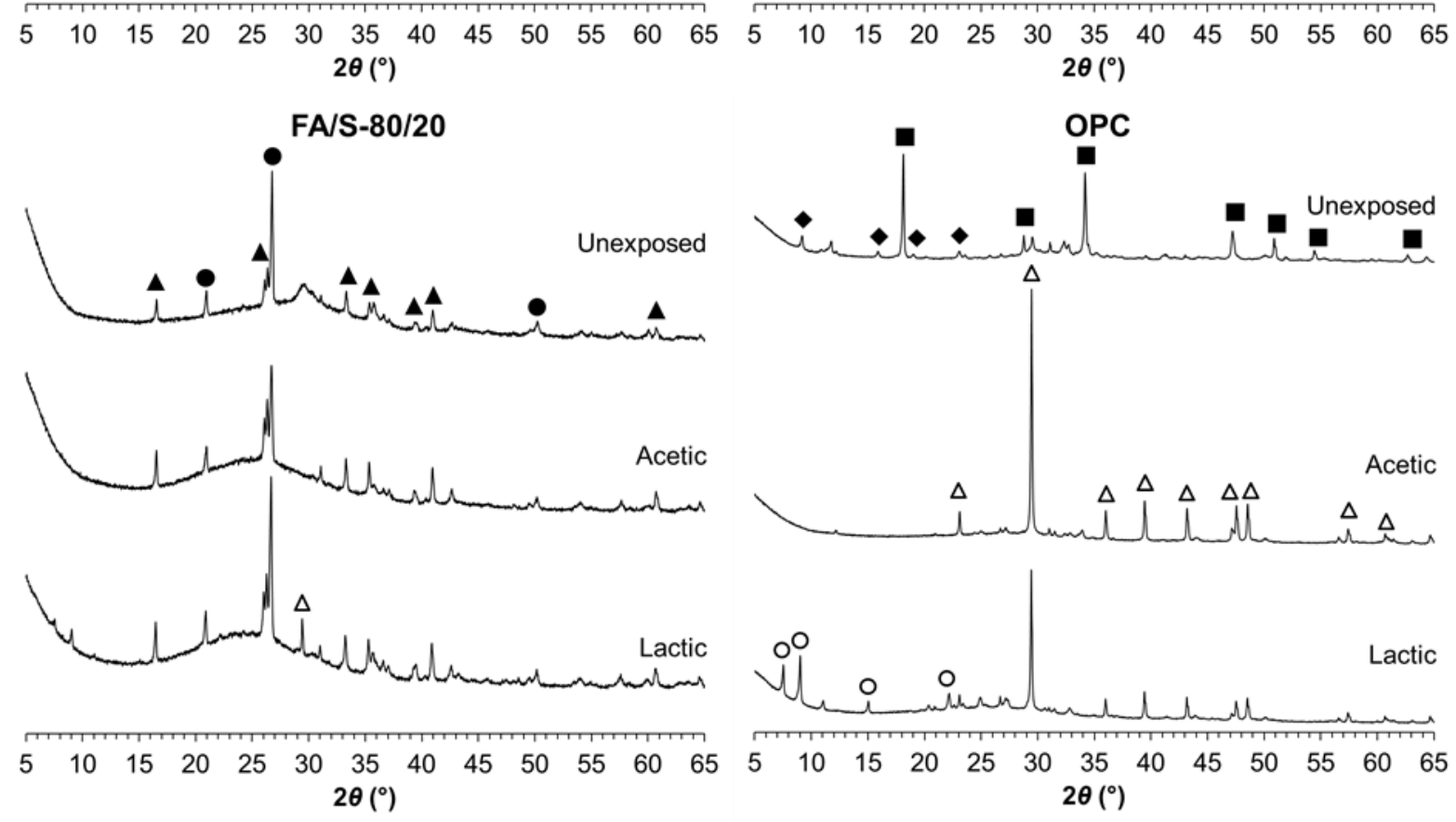

656 Fig. 11. XRD patterns of each paste mix after immersion in solutions of acetic and lactic acid for 3

657 weeks. 

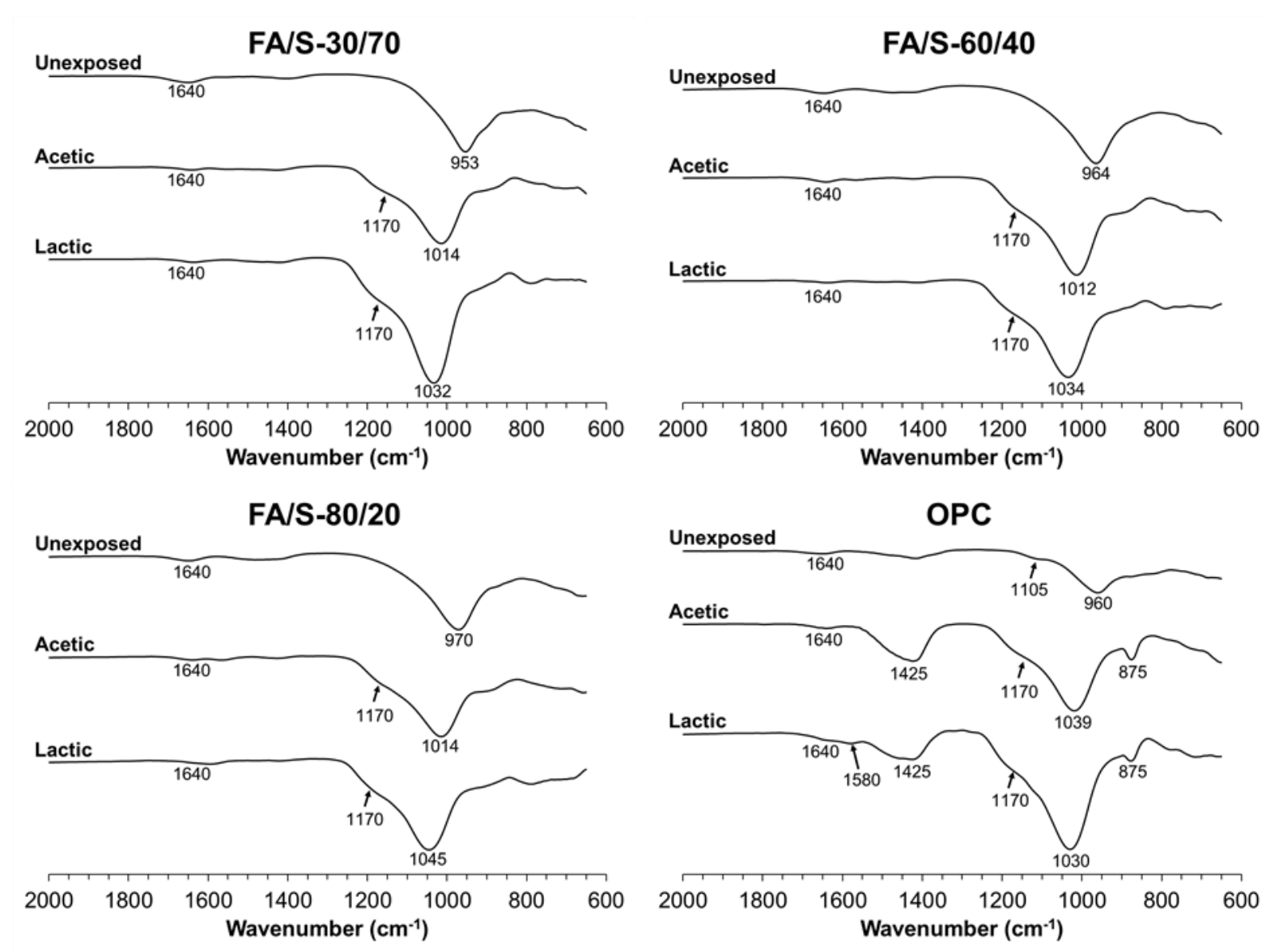

659 Fig. 12. FTIR spectra of each paste mix after immersion in solutions of acetic and lactic acid for 3

660 weeks. 


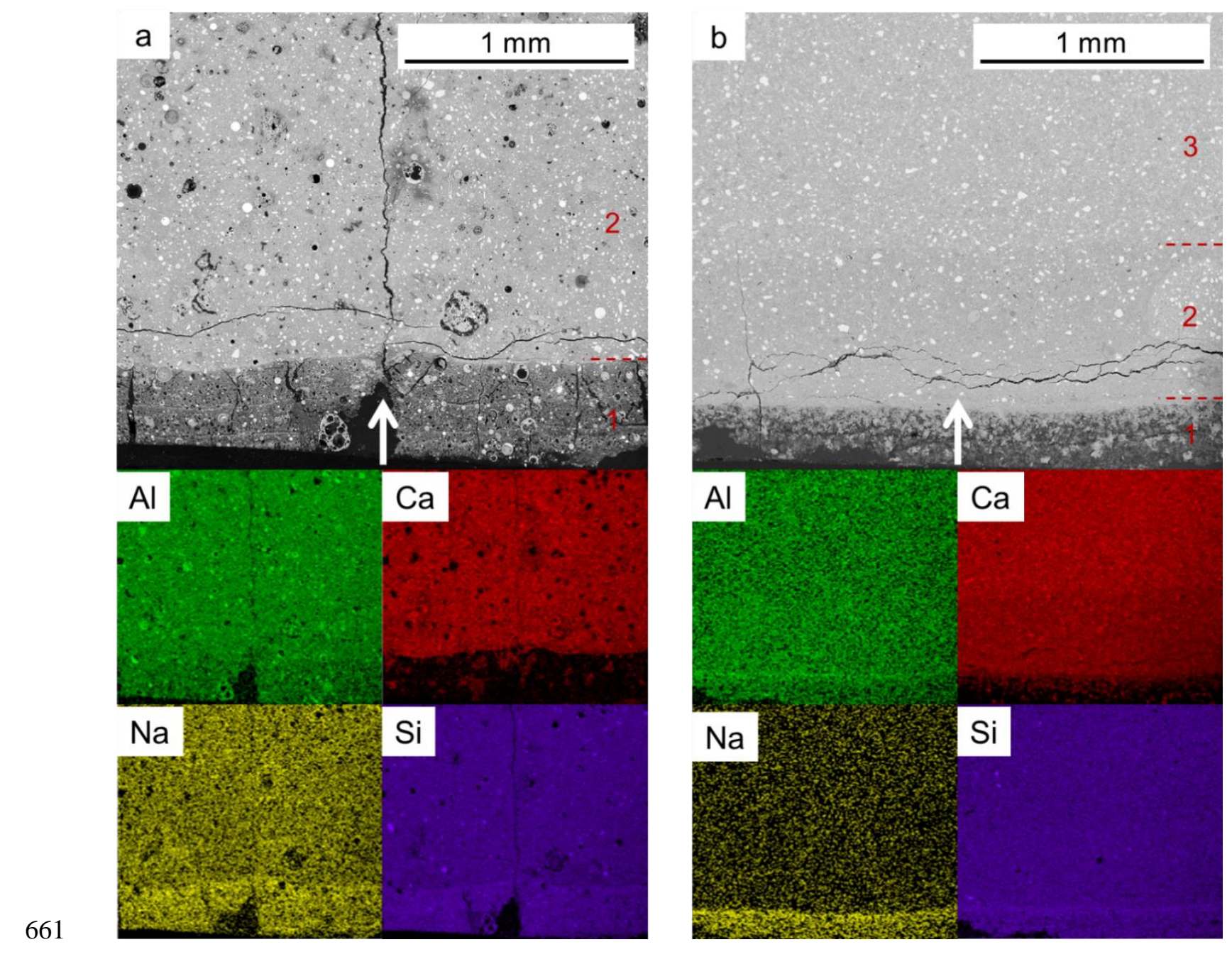

662 Fig. 13. SEM images and elemental analysis of the outmost layer of a) FA/S-30/70 and b) OPC paste 663 mixes after immersion in lactic acid for 3 weeks. 